\title{
Study on Bismaleimide Modified TDE-86 Epoxy Resin
}

\author{
Daofang Shi \\ Key Laboratory for Advanced Textile Composite of Ministry of Education \\ Tianjin Polytechnic University, Tianjin 300160, China \\ E-mail: shidaofang@163.com
}

Xiaoqing $\mathrm{Wu}$ (Corresponding author)

Tianjin Polytechnic University, Tianjin 300160, China

Tel: 86-022-2452-8052Ｅ-mail:wuxiaoqing@tjpu.edu.cn

\begin{abstract}
In the study, BMI was modified by Ortho-diallyl Bisphenol A under certain conditions and got performed polymer. Epoxy resin was modified by the performed polymer using nadic methyl anhydride (MNA) as curing agent. The study investigated the manufacturability, thermal and mechanical properties of modified resin. The manufacturability of the modified resin was indicated by viscosity- temperature, viscosity- time and the gel time curves. Thermal properties of modified resin were characterized by means of dynamic mechanical analysis (DMA). According to per GB/T standard, mechanical properties of resin casting body like impact strength and tensile strength were tested. The results demonstrated that the viscosity of modified resin is below $200 \mathrm{mPa} . \mathrm{s}$ at $60^{\circ} \mathrm{C}$ and the gel time is $110 \mathrm{mins}$ at $120^{\circ} \mathrm{C}$. The modified resin can be used in the resin transfer moulding (RTM) process of all kinds of complex structural composites. The incorporation of the performed polymer improves the heat resistance of epoxy resin. The glass transition temperature $\left(\boldsymbol{T}_{\mathrm{g}}\right)$ of the modified epoxy resin is $201.2^{\circ} \mathrm{C}$ and improves $44^{\circ} \mathrm{C}$. The impact strength of the modified epoxy resin is $8.061 \mathrm{KJ} / \mathrm{m}^{2}$. The tensile strength and tensile modulu of the modified are $60.9 \mathrm{MPa}$ and $3.89 \mathrm{GPa}$. The present paper observed electron micrographs of impact fracture cross-section of modified resin systems. The results showed that the fracture of the modified resin is ductile fracture.
\end{abstract}

Keywords: Epoxy resin, Bismaleimide, Ortho-diallyl Bisphenol A, RTM, Thermal property, Mechanical property

\section{Introduction}

Epoxy resin is a versatile and widely accepted matrix material for the fabrication of advanced composites, hardware components, electronic circuit board materials, radomes and missile equipment components because of its excellent bonding, physico-chemical, mechanical, dielectric aging characteristics and mechanical properties (Masaahi, K. and Kazuhik, N. 1999)(Leon Yu, T. and Chen Y. S. 2000). However, the inherent heat resistance of epoxy resin are low. To improve working performance of epoxy resin suitable for advanced engineering applications, the heat resistance and toughness of epoxy resin with appropriate chemical modifiers are essential. Many attempts have been made to modify epoxy resins with a high-performance engineering thermoplastic that has a high the glass transition temperature and toughness, such as polysulfone(PSF)(Giannotti M. I. and Galante M. J. 2003), poly(ether sulfone) (PES)(Bejoy, Francis. and Sabu, Thomas. 2006).Liquid rubber modied epoxy resin is also a commonly used method, such as CTBN(Garima, Tripathi. and Deepak, Srivastava. 2007), HTBP(Raju, Thomas . and Ding, Yumei. 2008). The effective improvement in toughness and heat resistance, where the thermoplastic forms a continuous phase with the epoxy spherical domain, or the thermoplastic and epoxy form a co-continuous phase. But the viscosity of the modified resins drastically increases, which causes the decrease in the handling. In addition, the $T \mathrm{~g}$ of the thermoplastic modified resin is equal to or only slightly higher than that of the unmodified resin because of the formation of the phase-separation morphologies. The incorporation of liquid rubber into epoxy resin can improve its toughness but the thermal property decrease markedly. It is evident that the gel time increases with the increase in the rubber concentration. As dilution increases with the addition of rubber, the concentration of reacting species gets reduced that impair reactivity. The rubber addition decreases stiffness of the network epoxy probably due to lowering in cross-linking density. Bismaleimides have been of particular interest and extensively studied(Premkumar, S., Karikal Chozhan, C. and Alagar, M. 2008)(Dinakaran, K., Suresh Kumar, R. and Alagar, M. 2003)( Rajasekaran, R., Alagar, M. and Karikal Chozhan, C. 2008). Bismaleimides, is essential, owing to their superior thermomechanical properties, viz. high thermal stability, high glass transition temperature, high char yield, excellent fire resistance, specific 
strength and specific modulus. Hence, in the present study, an attempt has been made to improve the thermomechanical behavior of epoxy resin, using BMI as chemical modifiers for epoxy resin.

RTM is an important process that could be employed to produce composites. Its objective is to satisfy the large range of performance requirements demanded by the automotive and aerospace industrial developments. RTM process is a versatile and efficient means for producing composites ranging from small, low performance items of simple shape to large, high-performance items of complex shape (Kim P. J. and Lee D. G. 2002)(Xiaoqing, Wu. And Ajit, Shenoi. 2006)(Naffakh, M., Dumon, M. and Gerard J. F. 2006). RTM process is amenable to automation in the manufacture of high performance composite parts. It offers the advantages of relatively low tooling and processing equipment costs, short cycle times, and the ability to make complex shapes.

The present study firstly used Ortho-diallyl Bisphenol A modified BMI under certain conditions then got the performed polymer. The performed polymer was used as a modifier to improve the heat resistance of epoxy resin. In this paper, the manufacturability, the glass transition temperature and the mechanical properties of the modified resin are investigated.

\section{Experimental}

\subsection{The preparation of modified resins and resin casting body}

Bismaleimide (4, 4'-bismaleimidodiphenylmethane), supplied by Hubei Shuangfeng Chemicals Co.,Ltd, China. Ortho- diallyl Bisphenol A was obtained from Shandong Laizhou Laiyu Chemical Co., Ltd, China. TDE-86 epoxy resin, supplied by Tianjin, China. The nadic methyl anhydride was used as curing agent and obtained from USA.

Performed polymer was synthesized with bismaleimide resin and Ortho-diallyl Bisphenol A by a certain ratio at $130-140^{\circ} \mathrm{C}$ and the lasting time of the reaction was $25-30$ mins. At $90^{\circ} \mathrm{C}$, epoxy resin was modified with the performed polymer using nadic methyl anhydride (MNA) as curing agent and stirred for 10 mins to ensure proper dispersion of performed polymer. The modified resins were injected into the mold at $60^{\circ} \mathrm{C}$ and degassed at $110^{\circ} \mathrm{C}$. The cured institution of unmodified and modified resin is $120{ }^{\circ} \mathrm{C} / 4 \mathrm{~h}+140{ }^{\circ} \mathrm{C} / 2 \mathrm{~h}+160^{\circ} \mathrm{C}$ $/ 2 \mathrm{~h}+180^{\circ} \mathrm{C} / 2 \mathrm{~h}+200^{\circ} \mathrm{C} / 2 \mathrm{~h}+220^{\circ} \mathrm{C} / 12 \mathrm{~h}$.

\subsection{Performance Test}

\subsubsection{Measurements viscosities of the modified resin}

The manufacturability of the modified resin was performed using Brookfield DV-II+Pro VISCOMETER, USA. Viscosity-temperature curve and Viscosity-time curve were studied in the paper. The gel time was a key factor for RTM.

\subsubsection{Dynamic mechanical thermal analysis (DMA)}

The dynamic mechanical thermal analysis was performed using NetzschDMA242 Analyzer, Germany. The analysis was carried out from 30 to $300^{\circ} \mathrm{C}$ at a heating rate of $10^{\circ} \mathrm{C} / \mathrm{min}$, with a fixed frequency of $1 \mathrm{~Hz}$. Dynamic modulu and loss modulu were obtained by the compression mode for the sample of size $5 * 5 * 2 \mathrm{~mm}^{3}$. The temperature corresponding to the maximum in $\tan \delta$

versus temperature plots was recorded as a measurement of the glass transition temperature $\left(\boldsymbol{T}_{\mathrm{g}}\right)$.

\subsubsection{Mechanical Properties}

The impact strength of the unnotched specimens was determined by Instron9250HV Impact Tester, USA, using rectangular specimens of $120 * 15 * 10 \mathrm{~mm}^{3}$ according to GB/T2571-1995. The impact test was carried out at room temperature and the impact energy was reported in Milli Joules.

The tensile test was also performed in AG-250KNE testing machine, Japan, at a crosshead speed of $2 \mathrm{~mm} / \mathrm{min}$, according to GB/T2568-1995. The values were taken from an average of at least five specimens. The measurement of resin casting body mechanical properties was performed at room temperature.

The fracture surfaces of the unnotched specimens from impact measurement were analysed using KYKY 2800 scanning electron microscope. All the specimens were sputter coated with gold before taking the micrographs.

\section{Results and discussion}

\subsection{The manufacturability of the modified resin}

RTM process requires matrix resin has lower viscosity and the maximun value should not exceed $1000 \mathrm{mPa}$.s. Low-viscosity material resin is conducive to enhancing the full infiltration of the material and rule out the bubbles between the fabric layers and fiber bundles. It is useful to reducing injection pressure. Fig 1 is 
viscosity-temperature curve of the modified resin. It shows that the viscosity is in excess of $1200 \mathrm{mPa} . \mathrm{s}$ at room temperature and decreased with a rise of temperature. The viscosity of the modified resin rapidly declines with increasing temperature when the temperature range for testing is from room temperature to $60^{\circ} \mathrm{C}$. But the change of the viscosity is very little when the temperature range for testing is from $60^{\circ} \mathrm{C}$ to $120^{\circ} \mathrm{C}$. This phenomena indicated that the modified resin is very temperature-sensitive at low temperature. Optimal resin viscosity of RTM process is below $500 \mathrm{mPa}$.s for impregnation and the cure schedules vary from several minutes to several hours. Fig 1 shows that the viscosity of the modified resin is below $200 \mathrm{mPa} . \mathrm{s}$ at $60{ }^{\circ} \mathrm{C}$ and suitable for filling mold of RTM process. RTM process not only request low viscosity of matrix resin but also require the low viscosity to keep a duration to fill mold. Fig 2 is viscosity-time curve of the modified resins at $60{ }^{\circ} \mathrm{C}$. It shows clearly that the viscosity change of the modified resin is little by heating for 24 hours at $60{ }^{\circ} \mathrm{C}$. The viscosity of the modified resin increases $80 \mathrm{mPa}$.s. The modified resin still has excellent manufacturability and can meet RTM process of all kinds of complex structural composites.

The gel time of matrix resin is an important index because the process of resin infiltrate fiber must be completed before resin gel. The mold filling process, which can take several minutes or hours, is critical to obtain a good quality product. The curing reaction is apparently inactive in this injection stage. This time duration is known as the incubation period. It should be short, yet long enough to complete the resin injection in the mold. The resin must fully wet out the reinforcements, so that the cured product contains no voids or dry spots. Any voids present can result in a defect that can diminish the strength and quality of the cured part. Fig 3 is Viscosity - time curves of the modified resin at different temperatures. It shows that the gel time of the modified resin is $600 \mathrm{mins}$, $300 \mathrm{mins}$ and $110 \mathrm{mins}$ at $80^{\circ} \mathrm{C}, 100^{\circ} \mathrm{C}$ and $120^{\circ} \mathrm{C}$ respectively. With increase in temperature the time for attaining gel state decreases establishing the cure reaction as a thermally catalyzed. The study of the rheological behavior provides information of chain mobility of modified resin systems. At the early stage of curing reaction, the modified resin systems behave like viscoelastic liquid and have low viscosity $(<100 \mathrm{mPa} . \mathrm{s})$, after that, the viscosity grows abruptly at cure conversion due to the chain growth reaction and the time interval between viscosity jumping and gel is only about a $2 \mathrm{~min}$.

\subsection{The glass transition temperatures $\left(T_{g}\right)$ of the modified resins}

Dynamic mechanical analysis is a method that measures the glass transition temperature of polymeric material. The loss tangent is a sensitive indicator of crosslinking. At temperatures above $T_{\mathrm{g}}$, damping behavior decreases due to increase of crosslinking. Fig 4 shows the tan $\delta$-temperature curves of unmodified and modified resin at a heat in grate of $10^{\circ} \mathrm{C}$ per min from 30 to $300^{\circ} \mathrm{C}$. The unmodified epoxy resin exhibited a higher tan $\delta$ maximum value than modified epoxy resin. This indicated that the unmodified epoxy resin has lesser crosslink density than the modified resin, where as the incorporation of the performed polymer into epoxy has decreased the tan $\delta$ maximum value, due to the increased crosslink density. The glass transition temperature is the corresponding temperature value when $\tan \delta$ is maximum. The glass transition temperature was raised with incorporation of performed polymer from Fig 4. The increases in the values of $\boldsymbol{T}_{\mathbf{g}}$ is due to the homopolymerisation of the performed polymer rather than Michael addition reaction. Thus, Michael addition reaction reduces the crosslink density due to chain extension. The glass transition temperature of unmodified epoxy resin is $157.3^{\circ} \mathrm{C}$. The glass transition temperature s of the modified resin is $201.2^{\circ} \mathrm{C}$.

Fig 5 is Storage modulus- temperature curves of modified resin. It shows that the storage modulus decreased with temperature and the values remained constant after the glass transition region. The storage modulus of the modified resin was lower than that of the unmodified epoxy resin. Polymer materials have viscoelasticity. They occur hysteresis at the appropriate conditions of temperature and external force which called internal friction. It is commonly defined in relation to its own chemical structure. The value of storage modulus (E') is larger and $\tan \delta$ is lower when temperature is less than the glass transition temperature. This due to the temperature is not enough to make large motor unit or chain segment move. Only the changes of the bond angle and length caused small deformation. This deformation can keep pace with the change of external force so it is belong to elastic deformation. The internal friction is very small. Polymer material shows completely elastic property. The corresponding mechanical state is glassy state. Deformation of polymer material mainly due to chain segment begin to move under the influence external force near the glass transition temperature. The deformation take the dust of stress a phase angle $\delta$. The internal friction is clearly. The glass transition temperature, $\boldsymbol{T}_{\mathrm{g}}$, was assigned as the temperature where loss factor, tan $\delta$, was at maximum. The temperature continues to rise. It is enough high to make the large motor units and chain segments move freely. The movement chain segments can keep pace with change of external forces. So the internal friction is very small too. At this point the corresponding mechanical state is the high-elastic state. Since the temperature increase polymer materials would have stepped into viscoelastic state. The macromolecular can move freely. Storage modulu (E') falls rapidly. Irreversible 
permanent deformation of polymer material will cropped up. Deformation fully doesn't keep up with change of external forces.

\subsection{Mechanical Property}

The observed values for impact properties of unmodified and modified resin are presented in Table 1 . The incorporation of the performed polymer into epoxy decreases the impact strength from Table 1. The impact strength of the modified resin reduces by $25.9 \%$, when compared with that of unmodified epoxy system. This is due to increase in crosslinking density and the rigidity imparted by BMI. Fig 6 is Impact test curves of unmodified and modified resins. It shows that loads and energies of the impact fracture are decreased with the incorporation of performed polymer. The introduction of performed polymer into epoxy resin enhanced the values of tensile strength and modulus by $17.12 \%$ and $9.73 \%$, respectively, when compared with that of unmodified epoxy resin. This is due to the formation of the network structure between performed polymer and epoxy resin.

Fig 7 is SEM micrographs of impact fracture cross-section of unmodified and modified resin. Fracture of unmodified and modified epoxy resin have obvious fracture origin from Fig 7(a) and (b). Generally, brittle fracture of the fracture surface is smooth as a mirror. With the transition to ductile fracture, fracture surface gradually become scaly convex-concave surface. The fracture surface is coarser and the toughness is better. The toughness of modified resins is decreased with the incorporation of the performed polymer from Fig 7.

\section{Conclusions}

The manufacturability of the modified resin is very excellent. The viscosity of the modified resin is below $200 \mathrm{mPa}$.s at $60^{\circ} \mathrm{C}$ and increase $80 \mathrm{mPa}$.s by heating for 24 hours at $60{ }^{\circ} \mathrm{C}$. The gel time of the modified resin is $600 \mathrm{~min}, 300 \mathrm{~min}$ and $110 \mathrm{~min}$ at $80^{\circ} \mathrm{C}, 100^{\circ} \mathrm{C}$ and $120^{\circ} \mathrm{C}$ respectively. The modified resin could be used in RTM process of all kinds of complex structural composite.

The thermal properties of the modified resin were compared with unmodified epoxy resin. The value of the glass transition temperature of the modified resin is $201.2^{\circ} \mathrm{C}$ and improves $44^{\circ} \mathrm{C}$.

The incorporation of the performed polymer into the epoxy system reduced the impact strength to an extent by $25.9 \%$, when compared with that of unmodified epoxy system. This may be explained due to the high crosslinking and the heterocyclic-aromatic structure imparted by performed polymer. The tensile strength and modulus of the modified resin are improved

The introduction of the performed polymer into epoxy resin enhanced the values of tensile strength and modulus by $17.12 \%$ and $9.73 \%$, respectively, when compared with that of unmodified epoxy resin. Fracture of unmodified and modified resin is obvious brittle fracture.

\section{Acknowledgments}

The authors wish to thank the Tianjin Municipal Science and Technology Commission, China, for sponsorship of this research under the contract, 08JCZDJC24500, the Foundation of Tianjin Municipal Education Commission, China.

\section{References}

Bejoy, Francis. and Sabu, Thomas. (2006). Diglycidyl ether of bisphenol-A epoxy resin-polyether sulfone /polyether sulfone ether ketone blends: phase morphology, fracture toughness and thermo-mechanical properties, J Colloid Polym Sci, 285:83-93.

Dinakaran, K., Suresh Kumar, R. and Alagar, M. (2003). Preparation and characterization of bismaleimide-modified bisphenol dicyanate epoxy matrices, J Appl Polym Sci, 90: 1596-603.

Garima, Tripathi. and Deepak, Srivastava. (2007) Effect of carboxyl-terminated poly (butadiene-co-acrylonitrile) (CTBN) concentration on thermal and mechanical properties of binary blends of diglycidyl ether of bisphenol-A (DGEBA) epoxy resin, J Materials Science and Engineering A, 443: 262-269.

Giannotti M. I. and Galante M. J. (2003). Role of intrinsic flaws upon flexural behaviour of a thermoplastic modified epoxy resin, J Polymer Testing, 22: 429-437.

Kim P. J. and Lee D. G. (2002). Surface quality and shrinkage of the composite bus housing panel manufactured by RTM, J Compos Struct, 57:211-220.

Leon Yu, T. and Chen Y. S. (2000). Physical aging of epoxy resin blended with poly(ether sulfone): effect of poly(ether sulfone) molecular weight, J Polym Res, 7: 257-66. 
Masaahi, K. and Kazuhik, N. (1999) Synthesis of a bifunctional epoxy monomer containing biphenyl moiety and properties of its cured polymer with phenol novolac, J Appl Polym Sci, 74: 690-698.

Naffakh, M., Dumon, M. and Gerard J. F. (2006). Study of a reactive epoxy-amine resin enabling in situ dissolution of thermoplastic films during resin transfer moulding for toughening composites, J Composites Science and Technology, 66: 1376-1384.

Premkumar, S., Karikal Chozhan, C. and Alagar, M. (2008). Studies on thermal, mechanical and morphological behaviour of caprolactam blocked methylenediphenyl diisocyanate toughened bismaleimide modified epoxy matrices, J European Polymer Journal , 44: 2599-2607.

Rajasekaran, R., Alagar, M. and Karikal Chozhan, C. (2008). Effect of polyethersulfone and N,N'-bismaleimido-4,4'-diphenyl methane on the mechanical and thermal properties of epoxy systems, $J$ Exp Polym Lett, 2: 339-348.

Raju, Thomas . and Ding, Yumei. (2008). Miscibility, morphology, thermal, and mechanical properties of a DGEBA based epoxy resin toughened with a liquid rubber, J Polymer, 49: 278-294.

Xiaoqing, Wu. And Ajit, Shenoi. (2006). Measurement of braided preform permeability, J Composites Science and Technology, 66: 3064-3069.

Table 1. Impact properties of unmodified and modified epoxy resin

\begin{tabular}{|c|c|c|c|}
\hline & $\begin{array}{c}\text { Impact strength } \\
\left(\mathrm{KJ} / \mathrm{m}^{2}\right)\end{array}$ & $\begin{array}{c}\text { Tensile strength } \\
(\mathrm{MPa})\end{array}$ & $\begin{array}{c}\text { Tensile modulu } \\
(\mathrm{GPa})\end{array}$ \\
\hline TDE-86\#/MNA & 10.878 & 52 & 3.545 \\
\hline The modified resin & 8.061 & 60.9 & 3.89 \\
\hline
\end{tabular}

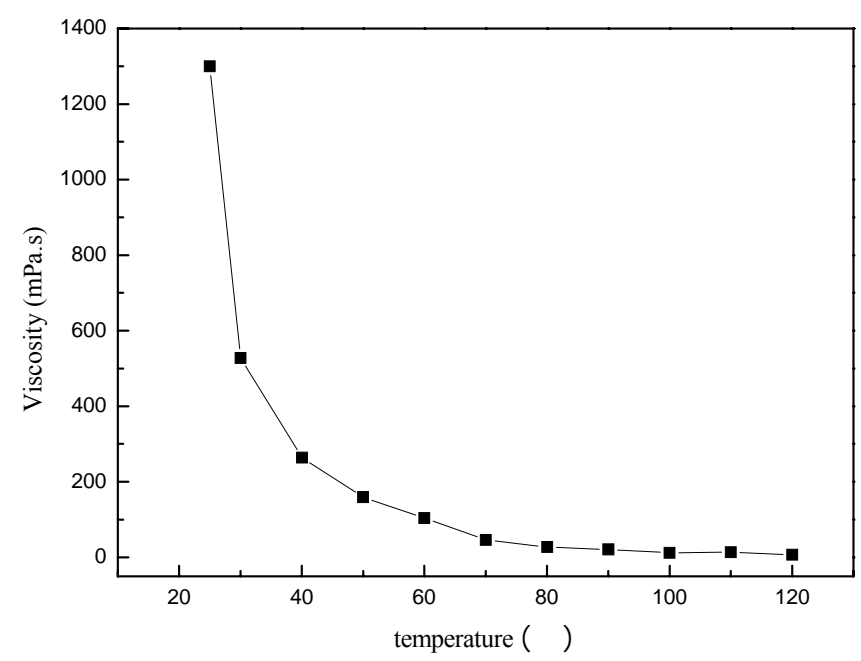

Figure 1. Viscosity- temperature curve of modified resin 


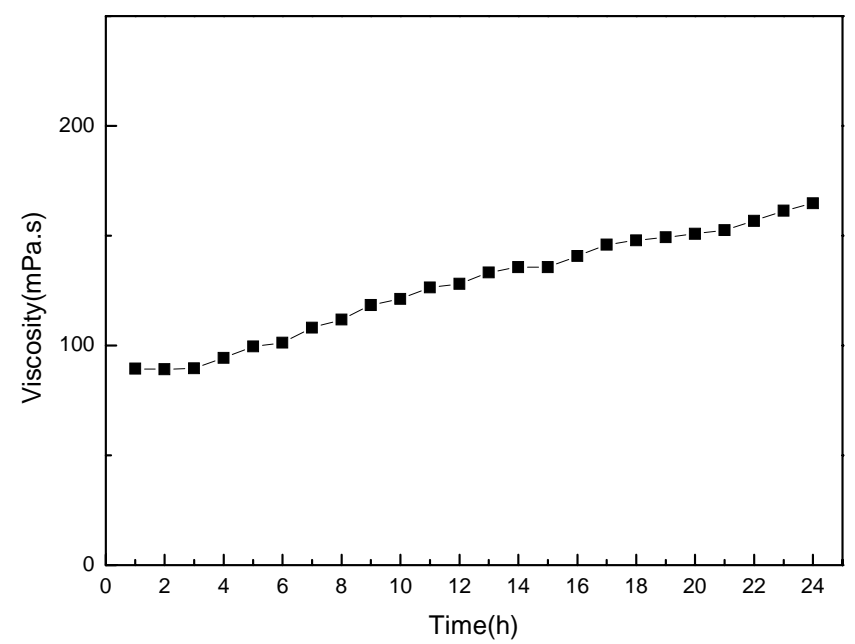

Fig2 Viscosity-time curve of modified resin

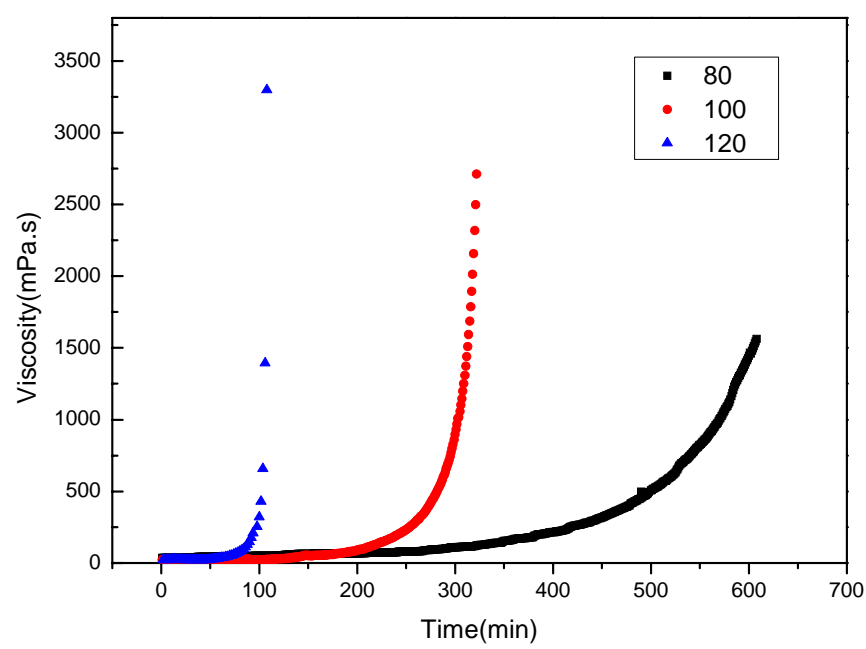

Figure 3. Viscosity-time curves of the modified resin at different temperatures

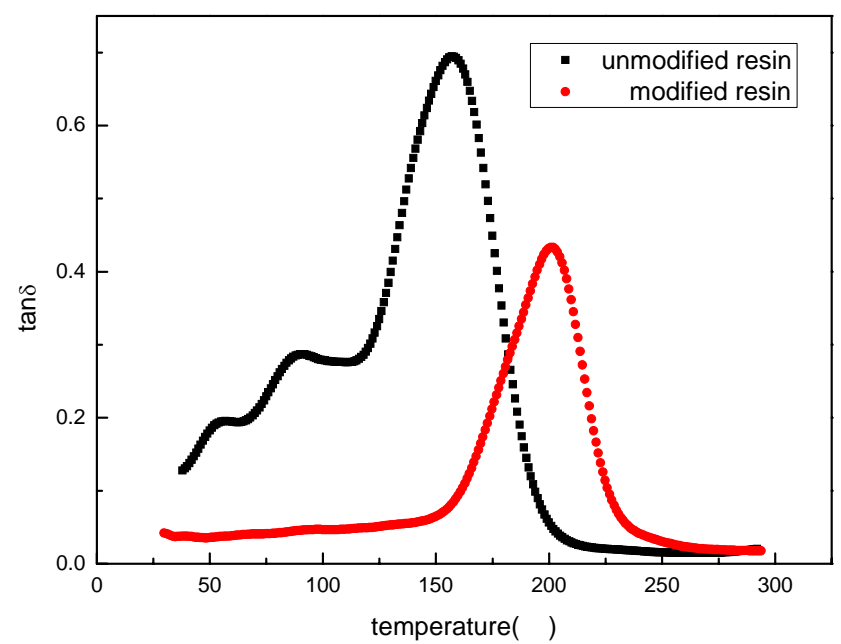

Figure 4. Variation of $\tan \delta$ with temperature 


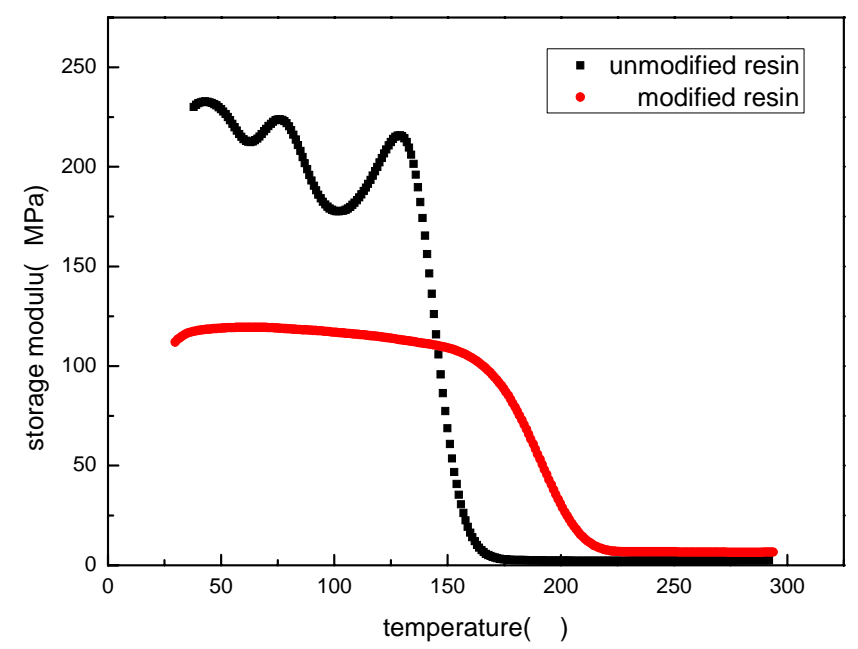

Figure 5. Variation of Storage modulus with temperature

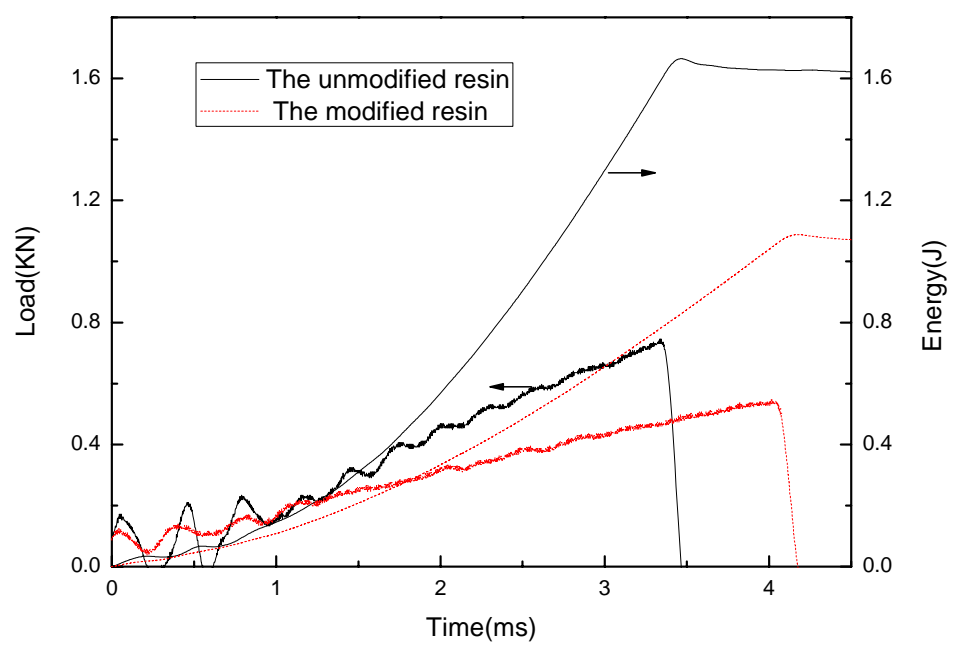

Figure 6. Impact test curves of unmodified and modified epoxy resin 

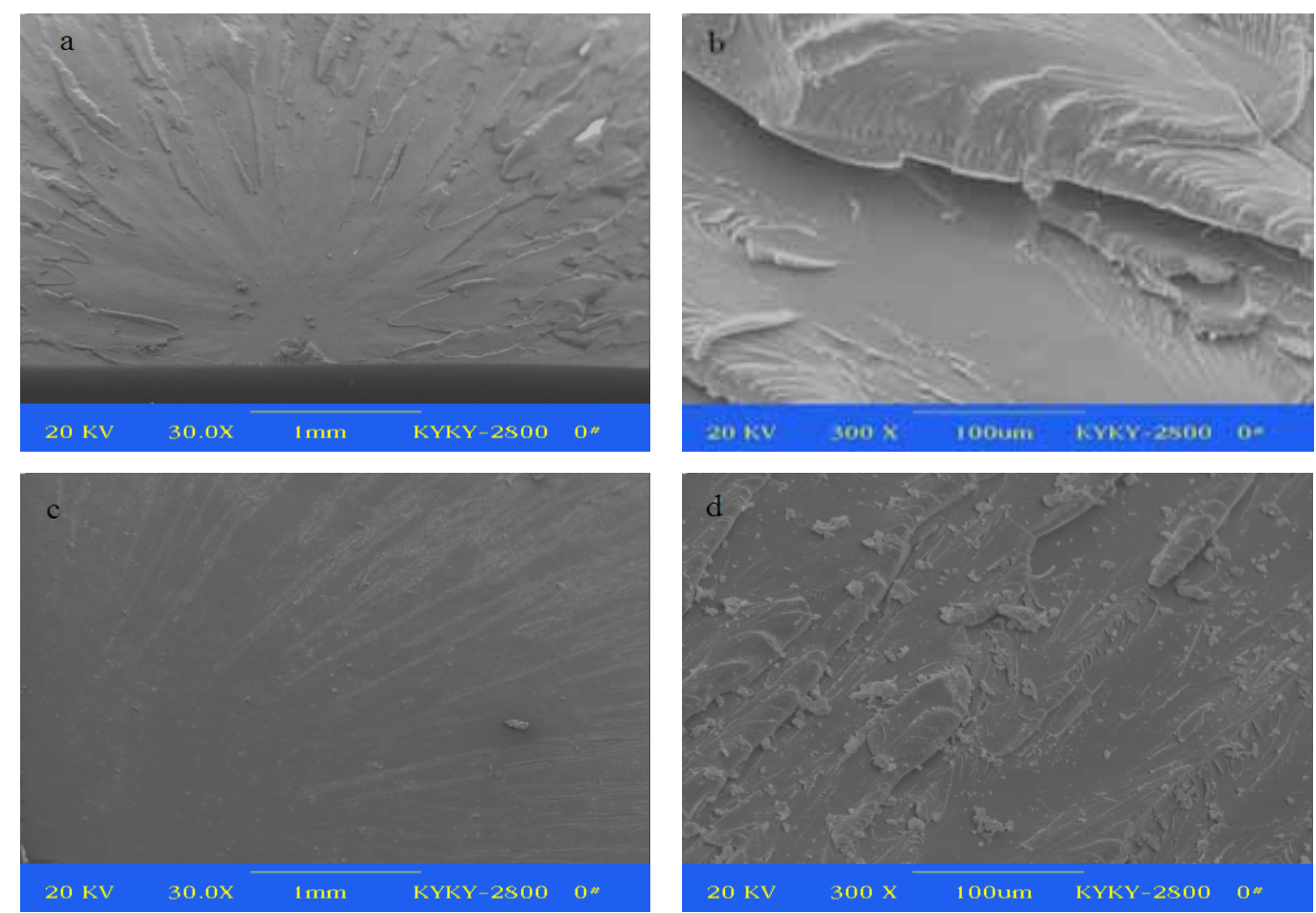

Figure 7. SEM micrographs of impact fracture surface of unmodified and modified resin (a) (b) unmodified epoxy resin (c) (d) modified resin 